\title{
ESTÁ TRISTE VENECIA: ANÓNIMO VENECIANO (ENRICO MARÍA SALERNO, 1970)
}

Data recepción: 2013/06/18

Data aceptación: 2013/10/13

Contacto autor: fjgarcia@uma.es
Francisco Juan García Gómez

Universidad de Málaga

\section{RESUMEN}

Anónimo veneciano (Anonimo veneziano, Enrico Maria Salerno, 1970) fue una película de gran éxito en su momento, pero hoy está injustamente olvidada. Pese a recursos estéticos propios de su época que han envejecido mal, es un filme muy interesante, que destaca por el tratamiento dramático de Venecia. Con un argumento romántico mínimo, la ciudad se erige en su principal protagonista, rehuyendo a la perfección el tópico turístico en que suelen caer muchos filmes ahí ambientados. Guión, puesta en escena, ritmo y música interactúan para crear una atmósfera melancólica, un sentimiento de tristeza y un halo mortuorio que impregnan toda la película.

Palabras clave: Venecia, Enrico Maria Salerno, arquitectura, melancolía, muerte.

\section{ABSTRACT}

Anonimo veneziano (Enrico Maria Salerno, 1970), was a very successful film in its time, but now is unjustly forgotten. With a minimal and romantic plot, the city is its main character, and avoids perfectly the common touristic stereotypes of other films set in Venice. Script, staging, rhythm and music interacting to create a melancholic atmosphere, a sad emotion and an aura of mortuary, which impregnates completely the film.

Keywords: Venice, Enrico Maria Salerno, architecture, melancholy, death.

Anónimo veneciano (Anonimo veneziano, 1970), debut en la dirección del actor Enrico Maria Salerno, es una película italiana a redescubrir y reivindicar ${ }^{1}$. Como sucede con tantos filmes, pasó, casi sin solución de continuidad, de gozar de un enorme éxito en toda Europa, incluida España, a ser un título prácticamente olvidado hoy en día, desconocido por las nuevas generaciones. Algunos de los factores que la llevaron al éxito son los que la terminaron conduciendo al ostracismo, y todos permanecen unidos a determinada estética de moda entre mediados de los 60 y mediados de los 70, que no ha envejecido demasiado bien. Entre ellos, además del abuso del zoom, se encuentra la música de Stelvio Cipriani, que a la vez supone el aspecto por el que actualmente más la recuerdan los pocos que la recuerdan.

Sin embargo, consideramos que se trata de una película sumamente interesante, y que, sin ser en absoluto una obra maestra, sí posee una calidad intrínseca más allá de esas convenciones coyunturales. Modas que afectaron a muchos otros títulos de esa época que, en cambio, sí continúan gozando de prestigio. Son varios los elementos que dan su valor a Anónimo veneciano, y ya los iremos analizando, pero sin duda el más destacado es el papel dramático de la propia ciudad de Venecia, en la que transcurre íntegramente el filme. En él nos centraremos principalmente en este artículo, sin olvidar los otros aspectos, ya que todos interactúan para obtener el resultado final.

\section{Romanticismo, melancolía y muerte en la laguna}

Valeria (Florinda Bolkan) llega en tren a la estación veneciana de Santa Lucia una mañana, 
procedente de Ferrara, donde vive con su actual pareja y sus dos hijos. Enrico (Tony Musante), un profesor de oboe del Conservatorio, la está esperando, pues le ha pedido que acuda. Ambos siguen casados, pese a que hace siete años que ella lo abandonó con su hijo Giorgio, rehaciendo su vida con un rico ferrarés, Emilio, con quien luego tendría una niña. Valeria desconfía de Enrico y de la causa de su cita, aunque piensa que está relacionada con la inminente implantación en Italia de la ley del divorcio (1970). A lo largo de paseos por Venecia rememorarán (tanto en diálogo como en forma de flashbacks) su antigua vida en común, hablarán de sus nuevas vidas, discutirán, pelearán y hasta Enrico, celoso pese a su actitud cínica, abofeteará a Valeria. Tras almorzar, él le confesará el motivo de su cita: está enfermo de cáncer, y no le quedan más de seis meses de vida. La ha llamado para despedirse. A partir de entonces la actitud de Valeria cambia, aflorando sin reservas el amor que ambos se siguen profesando, y que habían estado reprimiendo. En la casa de Enrico deciden disfrutar de las horas que aún les quedan antes de que Valeria parta en el último tren a Ferrara, el de las 21:35. Harán el amor y luego él ensayará el concierto barroco para oboe Anónimo veneciano (en realidad de Alessandro Marcello), que a última hora de la tarde grabará con su orquesta. Tras dejar la casa, continuarán el paseo y se despedirán en la antigua iglesia de San Vidal, donde se graba el concierto. Valeria asistirá a los primeros compases del Adagio, pero no podrá contener el llanto, por lo que Enrico detendrá

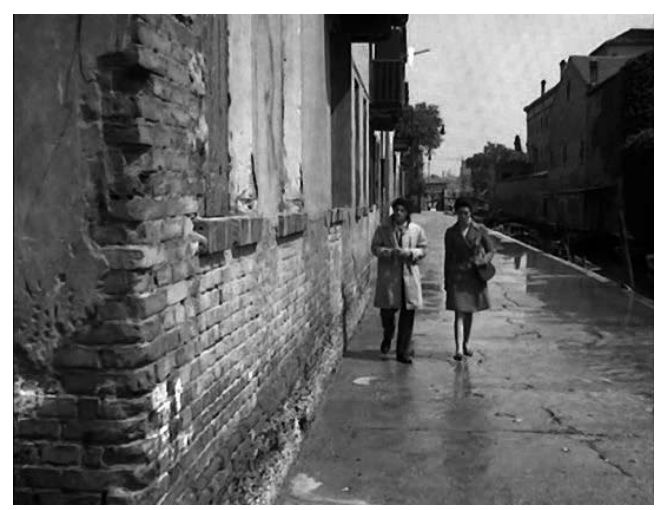

Fig. 1. Anónimo veneciano. El paseo por la Venecia menos tópica la interpretación y le dirá que puede marcharse, que la esperan en casa.

Anónimo veneciano es una de las grandes películas sobre Venecia, presentando una de las visiones más auténticas de la ciudad, empezando por la casi total ausencia de sus edificios más emblemáticos. (Fig. 1) Es decir, una imagen que rehuye del tópico, optando por mostrar la Venecia de los barrios populares, (Fig. 2) donde viven los pocos venecianos que no residen en Mestre, o incluso el puerto (Fig. 3). Y lo consigue con total éxito, erigiéndose en una de las obras paradigmáticas sobre el espíritu veneciano.

Pero deberíamos empezar por interrogarnos sobre qué sería el espíritu veneciano. Y la respuesta es que existen varios espíritus venecianos, no hay uno solo, porque Venecia, como cualquier ciudad, no es unidimensional, sino

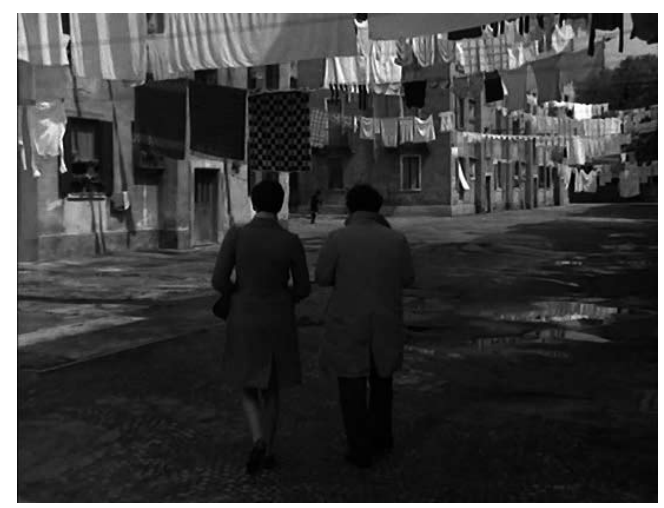

Fig. 2. Anónimo veneciano. La Venecia popular

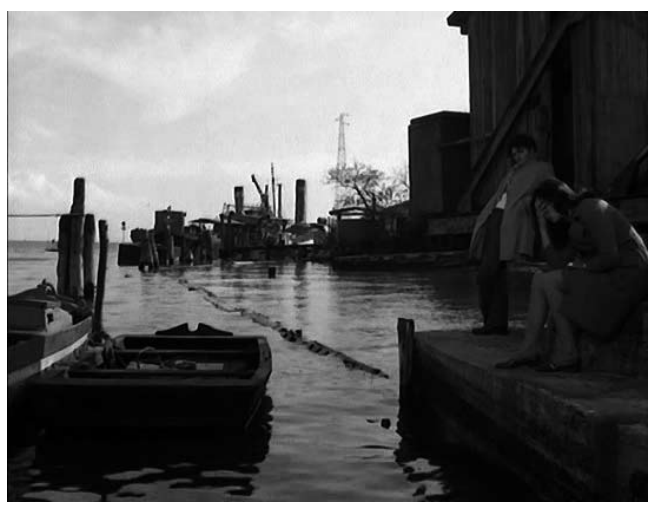

Fig. 3. Anónimo veneciano. El puerto veneciano 
poliédrica, multiforme, mostrando diversas caras, con frecuencia muy variadas, en ocasiones contrapuestas y hasta antitéticas. Y el cine las ha mostrado siempre. Por un lado, existe la Venecia romántica, la ciudad de los enamorados por excelencia junto a París, un lugar bello en el que se vive más intensamente que en otros el amor en pareja. Todos los sentimientos son sobredimensionados cuando el turista los vive con la persona amada, y si eso es así en cualquier sitio, e incluso el lugar más horrible del mundo queda transfigurado gracias a esa compañía, qué no será en una de las ciudades más hermosas. Muchas películas hay que muestran esta mirada romántico-turística. En cambio, cuando quien visita Venecia es una persona solitaria, como la solterona que interpreta Katharine Hepburn en Locuras de verano (Summertime, David Lean, 1955), el sentimiento que experimenta ante la imposibilidad de compartir su encanto por la ciudad se torna melancólico.

Pero también hay otra Venecia, muy diferente a la anterior, de la que viene a constituir una especie de "reverso tenebroso". Se trata de la Venecia que podría llamarse siniestra, resultado de su secular decadencia, fruto precisamente de las condiciones de emplazamiento que la hacen única. Venecia es una ciudad casi muerta, que apenas ha crecido desde el siglo XVIII, y que puede llegar a ser inquietante y peligrosa, como muchas películas han sido capaces de mostrar. Puede decirse que todo esto constituye la imagen mortuoria de Venecia, y la muerte estará presente en muchas películas ahí ambientadas. En el fondo, no son visiones totalmente antitéticas, pues las dos forman parte de la propia esencia de una ciudad polimórfica, que puede manifestarse de múltiples maneras.

Anónimo veneciano, al ser un melodrama, rehuye del aspecto siniestro de Venecia. Sin embargo, en ella se funden a la perfección la visión romántica y la fúnebre, lo que la convierte en un caso prácticamente único. En ese sentido, guarda alguna relación con El viaje (II viaggio, 1974), la última película dirigida por Vittorio de Sica, libre adaptación del cuento homónimo de Luigi Pirandello. Aunque en Venecia solo sucede la última parte, será allí donde ocurra el fatal desenlace. Adriana (Sophia Loren) es una viuda joven que, por una enfermedad del corazón, no puede emocionarse en exceso. Su cuñado Cesare (Richard Burton) la acompaña en un viaje que comenzó siendo médico y en el que terminan declarándose el amor que desde siempre se han profesado. Será en el "Hotel Danieli" de una Venecia fotografiada con mucho flou', donde Adriana muera víctima de las emociones intensas que le producen, por un lado, el amor consumado con Cesare, y por otro, las censuras y prejuicios que sabe que les aguardan a su regreso a Sicilia. Puede decirse que Adriana muere de amor en Venecia, la que sería una de las muertes más románticas que existen.

En Anónimo veneciano, la ciudad es una protagonista más, si no la principal, y su argumento tiene razón expresiva de ser justo en ese escenario. Al mismo tiempo, hemos dicho que elude con habilidad el tópico turístico: de los monumentos y enclaves más representativos solo veremos La Fenice, el Mercado de Rialto, San Giorgio Maggiore, el Palacio Ducal y el Campanile de San Marcos (y estos tres últimos solo desde lejos). Un protagonismo urbano que se incrementa por su levísima trama argumental. Es una película intimista-pese a ocurrir casi toda en exteriores-, más descriptiva que narrativa, repleta de toques poéticos, que pese a lo que pudiera parecer no cae en la lágrima fácil. Como sostiene Brunetta: "Salerno trova la giusta misura e il 'pudore' stilistico e narrativo necessari per non lasciari prendere la mano de una storia colma di elementi melodrammatici" ${ }^{3}$.

Puede decirse que Venecia aparece en clave metafórica, como símbolo de un reencuentro sin futuro y, sobre todo, como alegoría de la muerte que se cierne sobre Enrico ${ }^{4}$ : es una ciudad condenada a morir, y por eso mismo es la metáfora del protagonista. Varias frases del diálogo inciden en esa idea, y son casi siempre proferidas por Enrico. En el paseo en vaporetto al principio, dirá que la urbe "es bella hasta morir". (Fig. 4) Al preguntar Valeria si es verdad que se hunde, él argumentará que también desaparecieron Menfis, Nínive o Babilonia. En la Giudecca, cuando ella diga que es una ciudad putrefacta, que "esos colores se los da la podredumbre que la va devorando a través de los siglos. Se muere. Volverá a ser el fango que era", él replicará: "En 


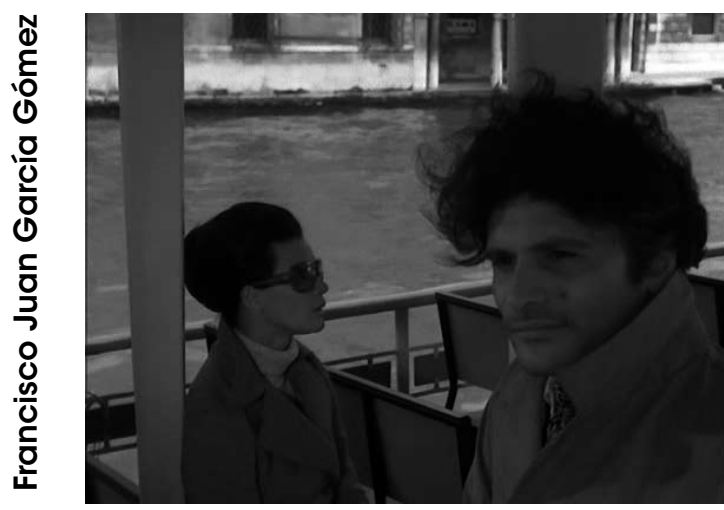

Fig. 4. Anónimo veneciano. Hablando de la decadencia de Venecia en el tenso paseo por el Gran Canal

eso está precisamente su belleza. Pero no todos son capaces de entenderlo. Se necesita llevar en sí el sentimiento de la muerte". Justo entonces le confiesa su enfermedad, produciéndose el gran punto de inflexión en su mínimo argumento. Más adelante, cuando pasean en góndola, Enrico, tras comentar el caso reciente de un ahogado, afirma que le gustaría fundirse con el mar. Como puede verse, el guión firmado por Giuseppe Berto (adaptando su propia novela) ${ }^{5}$ y Salerno redunda continuamente en la idea de la muerte, eje central -junto a su con frecuencia indisoluble el amor- de la película.

Sin embargo, en ningún momento se trata de una Venecia nocturna y siniestra, sino de una diurna, pero extremadamente triste. Toda la película transmite una profunda melancolía, que en la imagen se ve resaltada por la fotografía crepuscular de Marcello Gatti, que plasma adecuadamente el cromatismo de la época tardoinvernal en que se rodó. Por supuesto, el tono dominante del argumento (más la música, como luego analizaremos) es lo que hace que el espectador interprete la mayoría de las imágenes en ese sentido melancólico: de haber sido una comedia, esa misma Venecia se percibiría de otra forma. No obstante, hay ejemplos en los que la imagen habla por sí misma en clave de tristeza. El más significativo es la secuencia de montaje que, tras la escena erótica, muestra planos de embarcaciones semihundidas en la laguna y de las aguas azotando los bajos de los edificios. (Fig. 5) Son imágenes que redundan en una idea ex-

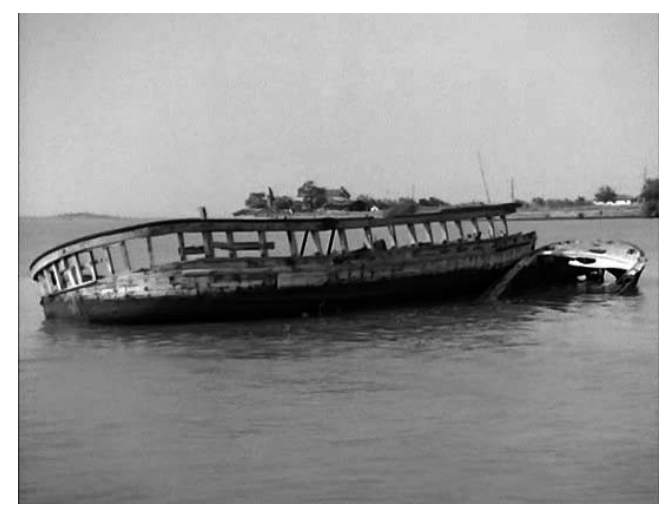

Fig. 5. Anónimo veneciano. El barco encallado en la laguna, perfecta metáfora de Venecia

presada anteriormente por Enrico: la de que Venecia parece un barco varado. Pero continuemos averiguando cuál es la Venecia concreta que nos muestra Anónimo veneciano.

\section{Un paseo inverosímil}

El cine siempre efectúa una recreación y reinvención de las ciudades, lo que patentiza su condición de arte fragmentario. Rodando en discontinuidad en lugares diferentes, mediante el uso del montaje ofrece al espectador un resultado que se presenta como creíble, como una continuidad espacial. Es, sencillamente, la aplicación del "efecto Kuleshov" 6 . Sin embargo, lo que hace en la mayoría de los casos es una alteración de la imagen urbana, creando una nueva ciudad que solo existe en el imaginario fílmico, como espacio dramático. Solo cuando conoce el urbanismo real, el espectador es capaz de advertir los cambios, produciéndose entonces un fenómeno de distanciamiento, al ponerse en evidencia que lo que está viendo es una construcción virtual, que un contraplano no corresponde espacialmente con el plano anterior. $Y$ cuando esto sucede en una película narrativa, el espacio termina llamando más la atención que el desarrollo de la historia: supone la advertencia de fallos de raccord en la configuración de ese rompecabezas urbano.

Un buen ejemplo sería Anónimo veneciano. Tras una primera visión, precisamente por su voluntad de rehuir de los lugares tópicos de Venecia, el resultado parece muy verosímil. Sin 
embargo, si la observamos con detalle, apreciaremos cómo, físicamente, resulta muy difícil, casi imposible, hacer todo el itinerario que la pareja recorre en menos de 12 horas, sobre todo porque se trata de un ritmo de paseo relativamente tranquilo (si bien en ocasiones se acelera, y Valeria así lo comenta), pautado con conversaciones y discusiones. Consideramos interesante profundizar en este aspecto, como sintomático de las reconstrucciones urbanas efectuadas por el cine, por lo que en este apartado intentaremos recrear el "nuevo plano" de Venecia fabricado por el filme.

La película comienza a las 9:30 en la Estación de Santa Lucia, como vemos en el reloj del andén donde Enrico recoge a Valeria7. Inmediatamente, tras su gélido saludo (resaltado por un montaje sincopado de primeros planos de ambos, enfrentados en plano-contraplano), toman un vaporetto en el Gran Canal, junto al puente degli Scalzi. La embarcación se dirigirá hacia Rialto: pasarán por la Pescheria, el Palazzo dei Camerlenghi y bajo el puente más célebre de la ciudad. Ahí comienza el primer flashback, en el que rememoran su enamoramiento en la universidad Ca'Foscari. Pero cuando se vuelve al presente diegético y vemos aparecer la Universidad, el vaporetto se encuentra en el Rio di Ca'Foscari, desde el que entrará en el Gran Canal a la altura de la Volta (su gran curva final), en cuya confluencia se sitúa el Palazzo Ca'Foscari. De hecho, ese hubiera sido el recorrido lógico si, al tomar el barco en la Fondamenta degli Scalzi, se hubiera dirigido hacia el Rio Nuovo, que enlaza con el Rio di Ca'Foscari, pero no siguiendo el camino que estaban haciendo. Por consiguiente, el resultado es un cambio completo de direccionalidad en el itinerario, un auténtico salto de eje. Tomarán tierra en el sestiere (barrio) de San Marcos, en un punto que no queda muy claro, aunque, tras deambular por varias calles, ella le pregunta si sigue viviendo por ahí, por San Samuele (él contestará que no, que ahora vive en la Giudecca) ${ }^{8}$. Después acudirán al Campo di Santo Stefano (cerca del palacio Pisani, sede del Conservatorio donde él es profesor), sentándose en la terraza de un café junto a la estatua a Nicolò Tommaseo. Desde allí se ve la iglesia desacralizada de San Vidal, donde (aún no lo sabemos) tendrá lugar el triste desenlace, unas horas más

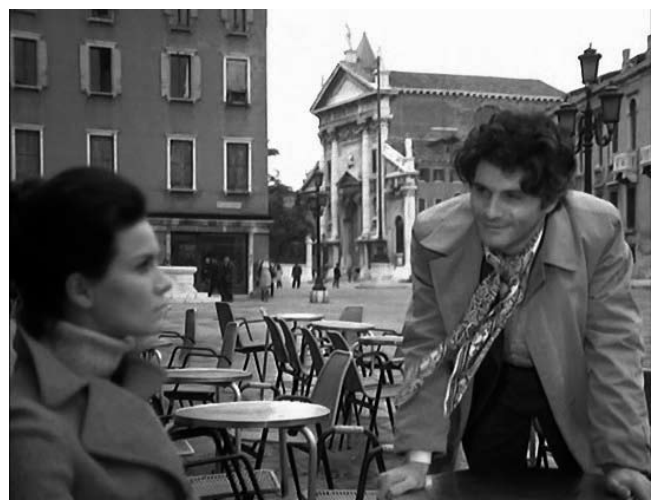

Fig. 6. Anónimo veneciano. En el café del Campo di Santo Stefano, con la iglesia de San Vidal al fondo

tarde, cuando la tensa desconfianza entre ambos ya haya desaparecido tras la revelación de Enrico. (Fig. 6)

Luego parece que caminan, con un fuerte viento, por lo que lógicamente debería ser el sestiere de San Marcos (si bien se ve la esquina de un campo con árboles que más parece de la zona de San Polo o Santa Croce). Sin embargo, poco después se les verá cruzando el Gran Canal en traghetto (las góndolas para tal fin), a la altura de la iglesia de San Stae. De ahí, se dirigirán a La Fenice, a la que pueden entrar porque Enrico es primer oboe de su orquesta. En esta sucesión de escenas volvemos a apreciar errores de continuidad, ya que, mientras parece que en la sucesión temporal solo han pasado unos pocos minutos, para hacer ese itinerario tendrían que haber seguido un largo y absurdo trayecto: de Santo Stefano (precisamente muy cerca del teatro de la ópera) al sestiere de Cannaregio (cerca de la estación) frente a San Stae, y de esta iglesia, situada en un extremo del barrio de Santa Croce, cruzar éste, el de San Polo y, de nuevo, el Gran Canal hacia La Fenice, ubicada en el centro del sestiere de San Marcos. En términos cartográficos, se trata de la parte más inverosímil de la película.

Tras abandonar el teatro, acudirán a la casa donde vivieron felices sus primeros años de casados, situada en un pequeño campo con iglesita y pozo. Aunque del templo solo se aprecia un fragmento de su fachada, su curvatura y otros detalles del campo (el brocal, las chimeneas) de- 
notan que se trata del Campo della Maddalena, en Cannaregio. (Fig. 7) Es decir, otro largo paseo desde La Fenice. Tras acontecer en ese lugar el momento más tenso de la película, con un desagradable bofetón de Enrico a Valeria a propósito de una nueva discusión sobre Emilio (que patentiza que aún sigue celoso de que ella haya rehecho su vida), pasamos, por corte de plano que lleva implícita una elipsis, a las anchas calles de la Giudecca y al Rio del Ponte Lungo (al fondo del cual se aprecia la isla de Sacca Sessola). Obviamente, desde Cannaregio hasta la isla de la Giudecca hay un buen trecho, que recorrerlo podría llevar cerca de una hora.

Tras una nueva pelea verbal, hacen las paces y Enrico dice que la va a llevar a un buen sitio?. En ese momento, veremos por primera vez una serie de planos de transición (cuatro) totalmente liberados del punto de vista de los personajes (que es el que ha primado en todo momento), a modo de insertos objetivos de la instancia narradora: el Gran Canal con la Pescheria, los Jardines Papadópoli, un movimiento de panorámica que muestra la Riva degli Schiavoni desde San Zaccaria hasta el Palacio Ducal, y una vista del Gran Canal a la altura de la Volta (el Palazzo Mocenigo y sus adyacentes). Luego volvemos a la pareja, que acude a comer a la bella pérgola de "Locanda Montin", en Dorsoduro, donde tendrá lugar una larga secuencia ${ }^{10}$. Tras este momento de descanso, y mientras escuchamos en off la voz de Enrico, volveremos a ver un plano que no corresponde a su punto de vista: las Zattere de Dorsoduro a la altura de la iglesia de

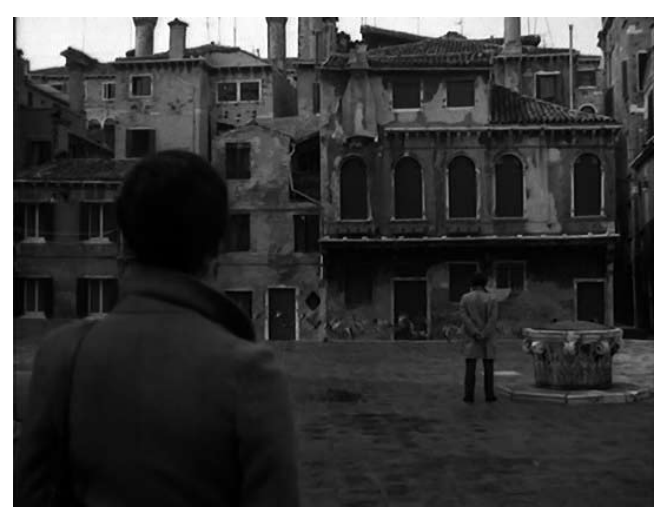

Fig. 7. Anónimo veneciano. La antigua casa de Enrico y Valeria en el Campo della Maddalena
Gesuati mientras pasa un barco por el canal de la Giudecca. Luego los veremos por callejuelas y, sin solución de continuidad, regresarán a la Giudecca, al Ponte Lungo, donde él le revelará su enfermedad. (Fig. 8) Mientras ella va asimilando la noticia, caminan junto al Squèro di San Trovaso, el pintoresco astillero de góndolas situado, de nuevo, en Dorsoduro. Posteriormente pasearán por el puerto, donde él reflexionará sobre su enfermedad y, más animado, le hablará del concierto que grabará. Justo después de abandonar el puerto, sabremos que aún no son las cuatro de la tarde, pues él le dice que a esa hora parte un tren.

Posteriormente vuelven a la Giudecca, a la casa de Enrico. Y esta es la célebre "Casa dei Tre Occhi" (1912-3), una obra del arquitecto Mario de Maria que funde con fortuna el neogótico con el liberty (el modernismo italiano), y que se sitúa muy cerca de la iglesia de las Zitelle. Desde la terraza veremos este templo manierista, y al fondo San Giorgio Maggiore. (Fig. 9) También desde la casa veremos la Salute, la Aduana y San Marcos, siendo casi la única vez que aparecen los monumentos más emblemáticos de Venecia. En la terraza se nos ofrecerá nueva información para continuar anclando la temporalidad: tras rechazar el tren hacia Ferrara de las 18:10, Valeria asistirá a las 20:15 al inicio de la grabación del concierto, tomando a las 21:35 el último tren. En ese momento darán las 16 en las Zitelle, y ella dirá que aún tienen cinco horas y media; cuatro hasta el ensayo, contestará él. Luego se abrazan con pasión. Tras la escena de amor, volverán a

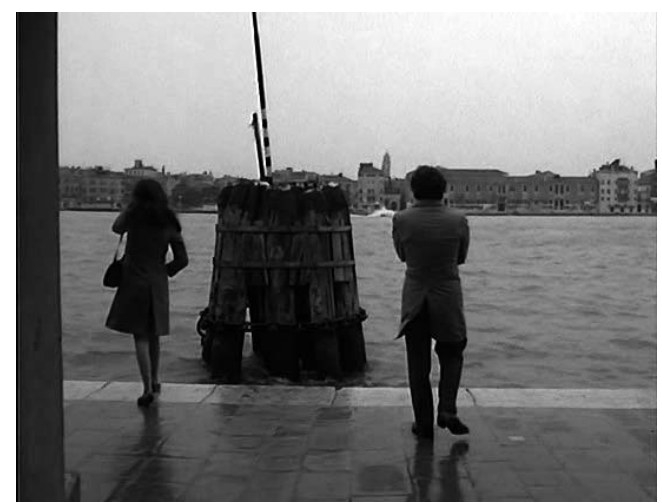

Fig. 8. Anónimo veneciano. En la Giudecca, justo antes de la confesión por Enrico de su enfermedad 


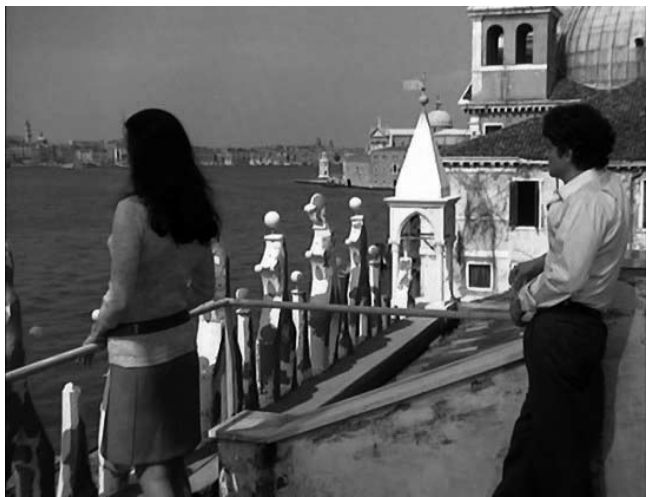

Fig. 9. Anónimo veneciano. En la terraza de la "Casa dei Tre Occhi". Al fondo, las Zitelle y San Giorgio Maggiore

verse planos desvinculados de la mirada de ellos, los ya comentados de embarcaciones y del agua que aluden simbólicamente a la decadencia de Venecia. Saben que disponen de pocas horas, y desean aprovecharlas intensamente saliendo a la calle, como dos enamorados. Al cerrar la puerta de la casa, la cámara volverá a ir por libre del punto de vista de ambos: la panorámica hacia el salón de Enrico, vacío, es un plano premonitorio del vacío que muy pronto habrá en la casa, una prefiguración de su próxima ausencia definitiva. A partir de entonces, la película se vuelve aún más triste si cabe, porque sabemos que en unas horas del tiempo real tendrá lugar su última despedida, y ese sentimiento impregna los veinte minutos diegéticos finales.

Pasamos a un plano del vaporetto a la altura de la isla de San Giorgio, dirigiéndose hacia San Marcos. En este sestiere, el más comercial de la ciudad, Enrico comprará un tocadiscos y un magnetofón para los hijos de Valeria. Saldrán de ahí por una de las características calles con soportales de las Mercerie, y llegarán hasta Rialto. Ya al otro lado del puente, pasearán por la Pescheria, para luego ir a la "Tessitura Luigi Bevilacqua", famoso telar y tienda de brocados en el barrio de Santa Croce, cerca de la iglesia de San Zan Degolà. Ahí Enrico le comprará brocados a Valeria, e incluso citará para sí mismo (voz over con el sonido interno de sus pensamientos) a Marcel Proust, quien escribió que las mujeres se olvidan de cualquier problema gracias a la ropa. Después de aquí los veremos dando un paseo en góndola por la laguna. (Fig. 10)

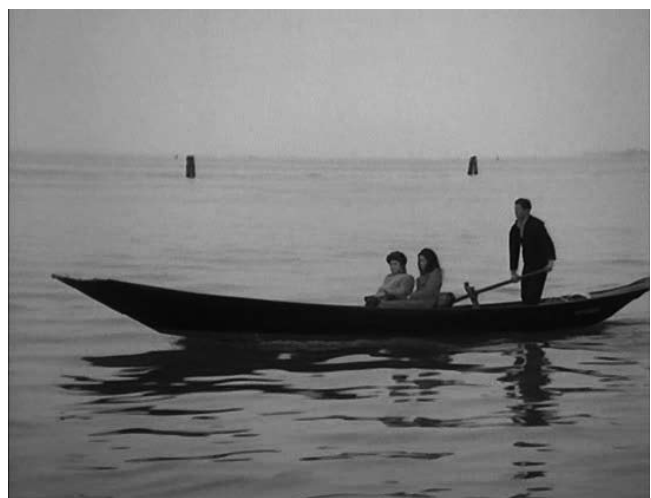

Fig. 10. Anónimo veneciano. Paseo en góndola por la brumosa laguna

Tras dos planos generales de transición que permiten una elipsis temporal (un movimiento de panorámica tomado a media tarde desde el Campanile de San Marcos, que va de San Giorgio a la Dogana; y una vista del Campanile y de la Riva degli Schiavoni anocheciendo), los veremos de nuevo caminando por las calles en el crepúsculo, dirigiéndose a la iglesia de San Vidal. Como ya dijimos, esta se sitúa al fondo del Campo di Santo Stefano, es decir, a cien metros del café donde habían estado por la mañana. Tras el comienzo del ensayo, Valeria regresará lenta y melancólicamente hacia Santa Lucia (aunque a ese paso tiene bastantes posibilidades de perder el tren).

Todo eso en once horas y media, en las que puede decirse que les cunde el tiempo. Muchas agencias de viajes pagarían por tener esta fórmula mágica para recorrer Venecia en una jornada. Evidentemente, no hay que juzgar una película en términos de estricto realismo planimétrico, pues muy pocas lograrían salir victoriosas de un análisis al respecto. Pese a esta ironía tras haber desmenuzado el paseo de Anónimo veneciano, eso no impide ni su verosimilitud (justamente por rehuir de los tópicos urbanos) ni, mucho menos, la sensación de tristeza que va progresivamente embargando al espectador.

\section{Tiempo melancólico}

El tratamiento del tiempo también resulta muy interesante en Anónimo veneciano, y aunque de un modo menos evidente que la puesta 
en escena o la música, viene a constituir otra de sus señas de identidad estilísticas. Se trata de una temporalidad extremadamente lenta: puede decirse que, a lo largo de la película, apenas "pasa nada", abundando los tiempos muertos según el cine mayoritariamente narrativo (el americano y sus imitadores). En sus 86 minutos, prácticamente solo veremos paseos por Venecia y, por momentos, casi no avanza la poca acción que hay, siendo una cinta más contemplativa que narrativa. No sigue una estricta organización de planteamiento, nudo y desenlace, y si hubiera que señalar un clímax, vendría a ser cuando Enrico confiesa la enfermedad. Evidentemente, sí que se cuentan cosas $y$, de hecho, se producen continuos cambios de sentimientos en los personajes, que van ritmando las conversaciones: desconfianza, cinismo, celos, odio, agresividad, ironía, humor, amor... Esos altibajos emocionales, perfectamente planteados por el guión, son los que permiten el desarrollo de la película, de su "historia", junto con el conocimiento que vamos haciendo de Enrico y de Valeria a partir de sus palabras y de los diversos flashbacks. También hay interesantes recursos de puesta en escena al respecto. Por ejemplo, en el travelling lateral que los sigue en la estación, Enrico marcha delante y Valeria atrás, expresando perfectamente su tensión y distanciamiento iniciales. (Fig. 11) O los cambios de peinado de ella: si al principio lleva el pelo recogido, cuando se va ablandando con los recuerdos en la comida, decide soltarse el pelo, como lo llevaba cuando vivían juntos.

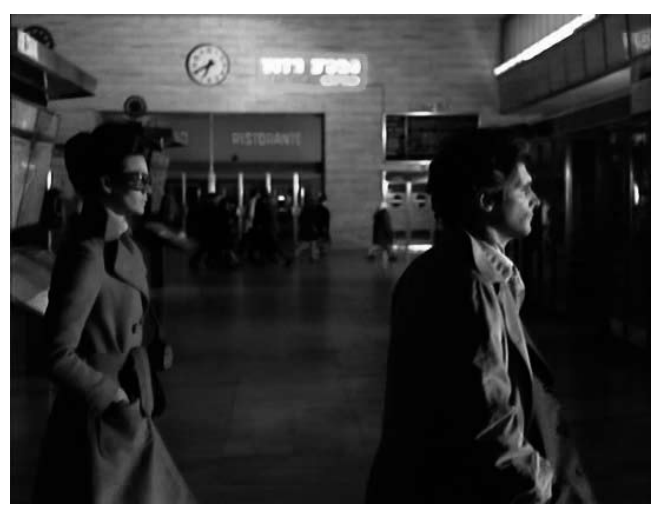

Fig. 11. Anónimo veneciano. Distanciamiento en la estación de Santa Lucía
Por estos motivos, puede relacionarse en cierta medida con algunas películas de autor de la época, o de décadas anteriores, sobre todo por el uso de los tiempos muertos. Sin embargo, dada la abundancia de diálogos, su temporalidad es muy distinta a la de, por ejemplo, un Antonioni. Compárese con el recorrido que Jeanne Moreau efectúa por las calles de Milán en La noche (La notte, 1961), y resultarán evidentes las diferencias. De hecho, de lo que más bien se trata es de una divulgación de ciertas tendencias del cine moderno: encontramos sus rasgos suficientes, pero a la vez recurre a mecanismos expresivos con una función de anti-distanciamiento (sobre todo la música), lo que la aleja de dicha modernidad. Como también la separa de esta la ausencia de la ambigüedad de sentido que tanto caracteriza la obra de esos cineastas: en esta película no se busca en ningún momento desorientar al espectador en el seguimiento de la (leve) historia.

Así, Anónimo veneciano, para el cine de autor italiano de los 60 y 70, viene a ser muy similar a lo que supone Un hombre y una mujer (Un homme et une femme, Claude Lelouch, 1966) respecto a la divulgación de los planteamientos de la nouvelle vague. Probablemente ello sea uno de los motivos del éxito de público de ambas, al fundir perfectamente el melodrama clásico con las aportaciones lingüísticas y narrativas de la modernidad, añadiéndole una música pegadiza (la de Lelouch compuesta por Francis Lai). En el caso de nuestra película resulta también capital el uso dramático de Venecia: una charla que podría haber sido en un interior (algo muy propio de muchas películas de autor), Salerno tiene la habilidad de trasladarla a la ciudad. Por supuesto, ambas cintas no son "falsos modernos", pero sí equilibrios afortunados entre el cine comercial y el de autor, patentizando que a veces sus límites son más imprecisos de lo que parece. Casi podríamos definirlas con el paradójico nombre de "cine de arte y ensayo comercial".

Anónimo veneciano también efectúa, en su desarrollo, una operación de cierto suspense que la distancia de las propuestas más radicales. Eso se aprecia sobre todo en el modo en que el guión va dosificando la información sobre la enfermedad de Enrico, hasta su confesión en el 
minuto 47. Sabemos que algo grave le sucede, pues lo insinúa en determinados comentarios (si él muriera ya no lo recordaría su hijo; habrá algo mejor que el divorcio para solucionar el fin de su matrimonio; siempre resalta el lado mortuorio de Venecia), además de que tiene un ataque (enfatizado por un cierre de zoom hacia su rostro) cuando simula dirigir la orquesta en La Fenice, saliendo entre bambalinas para ponerse una inyección en la pierna y luego tocarse dolorido la nuca.

Igualmente, la película muestra cierta relación con el fluir de la conciencia tan recurrente en los cines modernos desde los años 50. Incluso tiene algunos puntos de contacto con el cine de Alain Resnais, con su continua alternancia de presente y pasado. Sin embargo, Salerno borra cualquier posible ambigüedad al respecto: los breves flashbacks que puntúan la acción son siempre reconocibles para el público (mediante la actitud pensativa de los personajes, raccords visuales, flou y/o música), a diferencia de Resnais y otros autores que gustan de jugar con la confusión temporal.

En total hay siete flashbacks, cuya función es crear un contrapunto con el áspero y triste presente, al recordar los tiempos felices de la pareja, ayudando a incrementar la nostalgia. No obstante, mientras que en unos se aprecia que son recuerdos concretos de alguno de ellos o de los dos, otros se presentan como insertos de la instancia narradora. También hay unos más convencionales que otros. Los primeros, quizás los momentos menos satisfactorios de la película (por demasiado anclados a esa estética de época), suelen presentarse como breves secuencias de montaje con gran protagonismo de la música. El primero tiene lugar en el minuto 8: cuando pasan en el vaporetto bajo Rialto, recuerdan los días en que se conocieron en la Universidad. Tras volver al presente, él dice: "Ca'Foscari", y vemos el palazzo de la Universidad. En el segundo, en el min. 19, tras acariciar Enrico a Valeria, un raccord da paso a otra caricia, el día en que hicieron el amor por primera vez. El tercero es en el min. 49: tras confesar Enrico su tumor, la cámara mostrará el agua del canal de la Giudecca, pasando por corte al mismo lugar años antes, cuando Valeria disfrutaba un verano en un yate

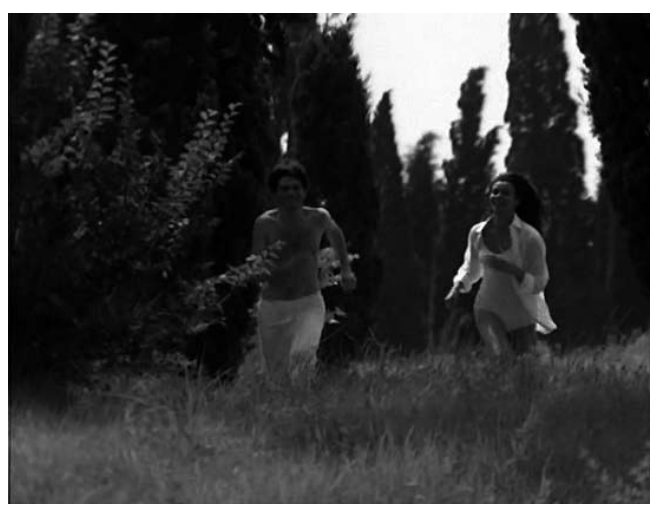

Fig. 12. Anónimo veneciano. Los lejanos días felices de la pareja

con Giulio, y Enrico los rodeaba en una motora. Pese a caer en cierta cursilería, resaltada por la música, su final contiene la imagen más dura del filme: del plano del niño se pasará a unas aguas sucias en las que flota un muñeco roto. En el último, el más largo (dos minutos), en el min. 68 (tras declarar Enrico su miedo y arrojar en la Peschería el oboe), vemos la típica secuencia de montaje de "días felices de una pareja" : corriendo, abrazándose y besándose en una islita de la laguna (al fondo parece verse Burano). (Fig. 12)

En cuanto a los menos convencionales, hay tres tipologías. Cuando en el min. 29 recuerdan, al contemplarla, su primera visita a su antigua casa, el flashback se resuelve mediante un plano secuencia en el que la dueña les va enseñando el piso visto en cámara subjetiva por ellos, cuyas

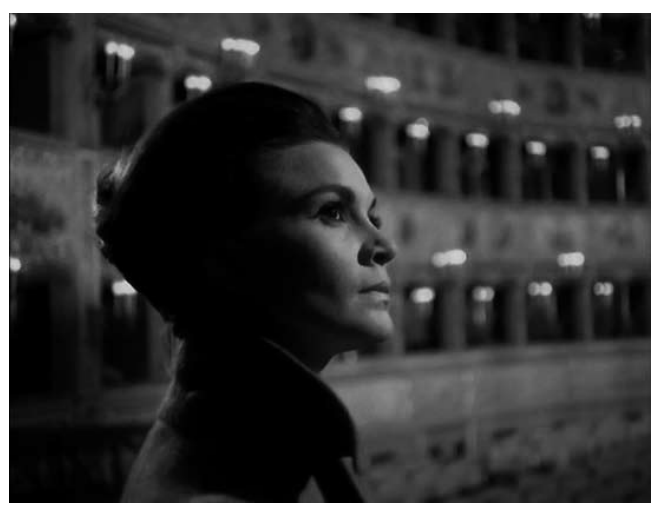

Fig. 13. Anónimo veneciano. Valeria recordando en La Fenice las ilusiones perdidas 


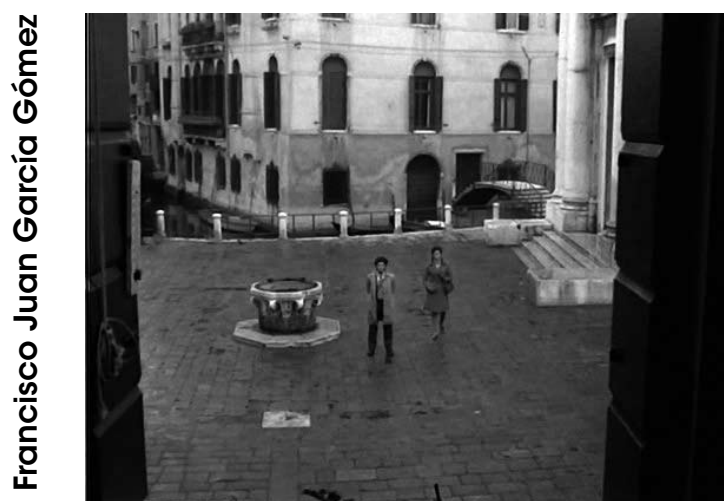

Fig. 14. Anónimo veneciano. Simultaneidad temporal en el Campo della Maddalena: el presente visto en plano subjetivo desde el pasado

voces escuchamos en off. Por otro lado, hay dos casos de simultaneidad temporal, de fusión de dos tiempos distintos en el mismo espacio. El primero se produce en La Fenice (min. 27), cuando Valeria se ve a sí misma unos años antes sentada en un palco, y la voz over de Enrico le cuenta sus proyectos profesionales. (Fig. 13) El segundo tiene lugar al final del flashback de la vieja casa: la señora abrirá la ventana y abajo los veremos a ambos en el presente. (Fig. 14) Es este un recurso que han utilizado Alf Sjöberg, Ingmar Bergman, Carlos Saura o Theo Angelopoulos. Pero, de nuevo, a diferencia de esos cines "autorales", Salerno intenta un mayor acercamiento al espectador, sobre todo con la música. Por último, hay flashbacks exclusivamente sonoros cuando están almorzando: mientras Valeria va mirando la pérgola, escucha interiormente las voces del día de su boda (de los invitados, del sacerdote, de Enrico).

\section{Adagio sesentero}

No puede negarse la enorme importancia que tiene la música en Anónimo veneciano. De hecho, la banda sonora compuesta por Stelvio Cipriani fue uno de los principales motivos del triunfo en taquilla de la película, convirtiéndose su disco en un éxito de ventas. Fue, además, el primer y más destacado éxito de su compositor, quien había debutado en el cine a mediados de los 60 con música para spaghetti westerns, en la estela marcada por Ennio Morricone. La partitura de Cipriani está muy ligada, tanto en estilo como en instrumentación, a determinados gustos musicales de finales de los 60 y principios de los 70, muy recurrentes en muchas bandas sonoras compuestas entonces. Ese contexto es lo que, por ejemplo, hace que su famoso tema principal tenga bastantes puntos de contacto con el aún más célebre que Francis Lai creó para Love Story (Arthur Hiller), precisamente en ese mismo año de 1970.

La música suena continuamente, si bien hay escenas en las que no está presente. La más significativa es la erótica, solo sostenida en el plano sonoro por los diálogos, que dotan de continuidad a un montaje fragmentado. Pero, en general, es bastante omnipresente, según el esquema de tema y variaciones: hay dos grandes temas que se van repitiendo variando en ritmo y orquestación (además de las cuerdas, tienen gran protagonismo piano, oboe, clarinete y clave). El principal y más célebre ya aparece desde los créditos, y se usa tanto en los instantes de mayor tensión como, con ritmo alegre, en los flashbacks que muestran su antigua felicidad (consideramos que en estos últimos es cuando peor funciona, y que quizás habrían ganado sin música). El segundo, más melódico y que en una de sus partes recuerda vagamente el Adagio de Albinoni, se utiliza sobre todo para los momentos más nostálgicos.

La de Cipriani es un claro ejemplo de música empática, por utilizar la terminología de Michel Chion, es decir, que apoya emocionalmente el contenido de la imagen, a la que comenta y puntúa ${ }^{11}$. Pero también es un sonido que colabora en la creación de una atmósfera determinada, de un clima que no siempre marcha a remolque de la imagen: en las vistas urbanas, es la música la que crea el clima principal, haciendo que la imagen deba ser entendida en un sentido (o tono) y no en otro ${ }^{12}$. Precisamente es este uso empático de una omnipresente música melódica otro de los rasgos que más la separan del cine de autor. Basta compararla con las "contemporáneas" y atonales partituras de Giovanni Fusco, Hans Werner Henze o Pierre Jansen para determinadas películas de Antonioni, Resnais o Chabrol, para advertirlo.

También se recurre a música preexistente, como el primer movimiento de la Quinta Sinfo- 
nía de Beethoven. Sus intensos compases sonarán cuando Enrico simule dirigir la orquesta en La Fenice, en una escena en la que se pone de manifiesto el fracaso de uno de sus sueños como músico, pues solo ha llegado a ser primer oboe. Se trata de un ejemplo de música interna, que suena en la cabeza de él: el espectador puede escuchar sus pensamientos sonoros.

Junto con la partitura de Cipriani, el otro gran protagonista musical de la película, a la que da el nombre, es el segundo movimiento (Adagio) del Concierto para oboe y cuerdas en re menor de Alessandro Marcello, un buen exponente de los brillantes compositores barrocos venecianos ${ }^{13}$. Su Adagio es una de las más hermosas, y tristes, piezas de la música clásica, al sacar el máximo partido al que quizás sea, junto al violín, el instrumento que mejor sabe expresar la melancolía: el oboe. Por eso, la presencia de su cantinela, como un lamento que flota sobre la neblina de la laguna, es lo que, junto a las imágenes de la despedida de Enrico y Valeria, confiere la intensa emotividad a la secuencia final en San Vidal. En ella, además, hay un buen uso de los caracteres diegético y no diegético de la composición. En la primera escena de las dos que componen la secuencia, escuchamos el Adagio como música diegética, interpretado por la orquesta que dirige Enrico y en la que actúa también como solista. (Fig. 15) Todo en San Vidal queda impregnado por la tristeza del oboe, incluyendo la pintura de Carpaccio y las esculturas del altar mayor. Tras interrumpir Enrico la grabación ante las lágrimas de Valeria y salir esta de la iglesia, volverá a sonar el Adagio. Sin embargo, al usarse el montaje paralelo para mostrarnos alternativamente a ambos protagonistas, para expresar su separación, lo escucharemos de manera diegética en las imágenes del interior de la iglesia, y no diegética cuando veamos a Valeria en la calle. Los dos planos finales, además, son bastante ilustrativos, poniendo de manifiesto las dotes como director de Salerno: en el primero, en la iglesia, un travelling hacia atrás se irá alejando de Enrico, hasta que desaparece tras una columna; en el segundo, con el punto de vista ya centrado en Valeria, un travelling la sigue en plano medio por la calle, más serena, hasta que la cámara hace un barrido hacia unas farolas, que nos muestra desenfoca-

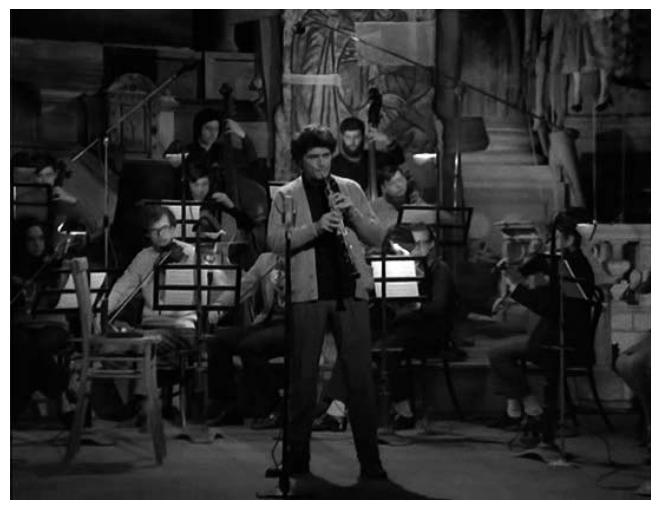

Fig. 15. Anónimo veneciano. Enrico y el Adagio final de Alessandro Marcello

das, imagen abstracta que cierra el filme. Qué mejor que la música de Marcello para expresar la infinita tristeza de una despedida irreversible. Ante su magistral intemporalidad, la partitura de Cipriani, pese a su calidad, palidece con su ritmo a la moda, y quizás por eso Salerno sabe que tiene que acabar la película con el oboe.

Por todos estos factores, Anónimo veneciano puede ser considerada la película veneciana por excelencia, a pesar de la reinvención fílmica que hace de su espacio físico: es la que mejor expresa lo que es Venecia y lo que significa "lo veneciano", como concepto y como estado de ánimo, por delante incluso de otras tan señaladas como Locuras de verano, Muerte en Venecia (Morte a Venezia, Luchino Visconti, 1971), Amenaza en la sombra (Don't Look Now, Nicolas Roeg, 1973) o El placer de los extraños (The Comfort of Strangers, Paul Schrader, 1990), por esa perfecta fusión que en ella se produce entre sus dimensiones romántica y mortuoria. Su historia no sería igual en otra ciudad, porque no puede separarse de Venecia: seguiría emocionando, por el papel que en ello desempeñan el guión, su tratamiento del tiempo, las interpretaciones y la música; pero carecería del imprescindible elemento dramático-simbólico que le aporta el omnipresente protagonismo de esa ciudad única. Al finalizar la visión de esa elegía fílmica que es Anónimo veneciano, nos acompaña un inevitable hálito de tristeza. Una tristeza como la de las piedras de la ciudad de la muerte, que se hunde sin remedio en su laguna. Que c'est triste Venice. 


\section{NOTAS}

1 Salerno (1926-1994) ya tenía entonces una extensa carrera como actor, en la que trabajaría (casi siempre como secundario) con directores como Valerio Zurlini, Roberto Rossellini, Florestano Vancini, Jean Becker, Dino Risi, Mario Monicelli, Luigi Magni, Dario Argento o Joseph Losey. También fue doblador, siendo suya, por ejemplo, la voz de Enrique Irazoqui en El Evangelio según San Mateo (II Vangelo secondo Matteo, Pier Paolo Pasolini, 1964). Tras Anónimo veneciano, su mejor filme y su mayor éxito, dirigiría El último adiós en Londres (Cari genitori, 1973), con Florinda Bolkan (en la plenitud de su exitosa carrera italiana entre finales de los 60 y finales de los 70), Catherine Spaak y Maria Schneider, y Eutanasia de un amor (Eutanasia di un amore, 1978), con Musante y Ornella Muti. Posteriormente haría lo propio con las miniseries Disperatamente Giulia (1989) y (en codirección por su fallecimiento) // barone (1995). El año antes de Anónimo veneciano, Salerno y el italoamericano Tony Musante ya habían coincidido como actores en el exitoso debut de Argento: El pájaro de las plumas de cristal (L'uccello dalle piume di cristallo, 1969, estrenada en 1970).

2 Un exceso de flou que fue característico de sus últimos títulos ambientados en el pasado, como El jardín de los Finzi-Contini (Il giardino dei FinziContini, 1971).

${ }^{3}$ G.P. Brunetta, Storia del cinema italiano. 4-Dal miracolo economico agli anni novanta 1960-1993, Editori Reuniti, Roma, 1998 (3 ${ }^{a}$ ed.), p. 446. Brunetta es uno de los estudiosos que mejor valora la obra de Salerno. De hecho, es uno de los pocos que lo tiene en cuenta, incluyéndolo en un grupo de cineastas que denomina "I piccoli maestri", caracterizados por su buen hacer: Pupi Avati, Gianni Amelio, Luigi Magni o Roberto Faenza. Ibídem., pp. 431-467. En otras historias generales no aparece (C. Lizzani, I/ cinema italiano. Dalle origini agli anni ottanta, Edi- tori Reuniti, Roma, 1992), ni siquiera en otras centradas en su época, salvo su labor como actor (L. Miccichè, Cinema italiano, gli anni 60 e oltre, Saggi Marsilio,Venezia, 1995, p. 68).

${ }^{4}$ Al poco de su estreno, Guarner ya dijo que planteaba "el proceso de desintegración de una pareja, paralelo al de la ciudad de Venecia, condenada a hundirse progresivamente hasta desaparecer". J.L. Guarner, "Cine romántico. Aproximación al género", en El cine. Enciclopedia del $7^{\circ}$ Arte (AA. VV.), Buru Lan, San Sebastián, 1973, t. 4, p. 115.

${ }^{5}$ Las novelas más destacadas del véneto Giuseppe Berto (1914-1978) fueron El cielo está rojo (II cielo è rosso, 1948) y El mal oscuro (II male oscuro, 1964), ambas llevadas al cine. También escribió una veintena de guiones, solo o en colaboración, como los de Mañana será tarde (Domani è troppo tardi, Léonide Moguy, 1950), Ana (Anna, Alberto Lattuada, 1951) y Celos (Gelosia, Pietro Germi, 1953). También colaboraría en el de la segunda película dirigida por Salerno: El último adiós en Londres.

${ }^{6}$ Una buena definición del efecto Kuleshov es la de "cualquier serie de planos que, en ausencia de un plano de situación, lleve al espectador a deducir un todo espacial a partir de la visión de solamente porciones de ese espacio". D. Bordwell y K. Thompson, El arte cinematográfico. Una introducción, Paidós, Barcelona, 1995, p. 258.

7 Sin embargo, tres planos antes, ese mismo reloj marcaba las 7:50, lo que supone un claro error de raccord. Luego, cuando ambos abandonen la estación, veremos que otro reloj marca las 18:40, lo que explica el siguiente fallo de continuidad, relacionado con la luz: al salir al exterior continúa el plano largo con travelling lateral que los ha seguido, dando paso sin corte a una panorámica en la que se aprecia que la luz en el Gran Canal es crepuscular; justo después, en el contraplano que encuadra la estación se advierte la luz solar de la mañana (por tanto, este es el plano verosímil en términos diegéticos).

${ }^{8}$ En la versión doblada dice erróneamente "la judería", lo que lleva a confusión: según esto, se situaría en el guetto, en el sestiere de Cannaregio, si bien luego comprobaremos que se halla en la Giudecca.

${ }^{9}$ Aquí parece haber otro error de raccord, pues el puentecito sobre el que han discutido, aunque se supone emplazado en la Giudecca al no haber ninguna elipsis tras un plano anterior del Rio del Ponte Lungo, más bien parece hallarse en Dorsoduro o San Marcos.

${ }^{10}$ La página web de este hotelrestaurante (hoy "Antica Locanda Montin") incluye entre sus imágenes fotogramas de esta secuencia: http:// www.locandamontin.com/

${ }^{11} \mathrm{M}$. Chion, La música en el cine, Paidós, Barcelona, 1997, pp. 232-236.

12 Es lo que Chion llama "valor añadido". M. Chion, op. cit., pp. 209210. Aquí parece estar rebatiendo sabiamente actitudes dogmáticas como la de Marcel Martin, quien desprecia sin más el acompañamiento musical lírico o dramático. M. Martin, El lenguaje del cine, Gedisa, Barcelona, 1996, pp. 137-142.

${ }^{13}$ La atribución de este concierto fue durante mucho tiempo controvertida, barajándose los nombres de Vivaldi y el más prolífico hermano de Alessandro Marcello, Benedetto. Pero el descubrimiento de la edición original (Amsterdam, 1716), zanjó la cuestión. Agradezco esta información al profesor Francisco Martínez González. Bach hizo una transcripción de este concierto para clave solo (BWV 974), y de hecho, tras la escena de amor, veremos a Enrico interpretarla al piano. En su partitura se lee Benedetto Marcello, lo que indica que aún se mantenía esa atribución, y que el título de Anónimo veneciano tiene sobre todo función poética, como si se quisiera redundar más en la melancolía, o como si el amor de los protagonistas estuviera ahí perdido, esperando a ser rescatado. 